\title{
Formation of surface nano/ultrafine structure using deep rolling process on the AISI 3 I6L stainless steel
}

\begin{abstract}
In the present work, effect of deep cold rolling process known as deep rolling on near-surface microstructure and hardness of an austenitic stainless steel has been evaluated. Deep rolling process using a ball-point device was carried out on the barshaped AISI 316L stainless steel specimens. The process was performed at 15 and 26 passes with $0.2 \mathrm{~mm} / \mathrm{s}$ longitudinal rate and $22.4 \mathrm{rpm}$ bar rotation. Microstructure and hardness were investigated by feritscope, $\mathrm{X}$-ray diffract meter, field emission scanning electron microscope and Vickers $\neg$ micro-indenter at $0.1 \mathrm{kgf}$. A composite microstructure, consisting of ultrafine and nano grains $(200 \mathrm{~nm}$ and $70 \mathrm{~nm})$, mechanical twins and strain-induced marten site, was observed in the near-surface regions. Surface hardness was increased from 210 to 450 and 500HV0.1 after 15 and 26 passes, respectively.
\end{abstract}

Keywords: stainless steel, deep rolling, nano/ultrafine, microstructure
Volume I Issue 3 - 2017

\author{
Abdolreza Jafari Tadi, Hosseini SR, Naderi \\ Semiromi M \\ Department of Materials Engineering, Malek-Ashtar University \\ of Technology, Isfahan 83 I45-I I5, IR Iran
}

Correspondence: Abdolreza Jafari Tadi, Department of Materials Engineering, Malek-Ashtar University of Technology, Isfahan 83|45-II5, IR Iran, Email abdolrezajafari68@gmail.com

Received: August 23, 2017| Published: September 25, 2017

\section{Introduction}

Austenitic stainless steels (ASSs) have an excellent corrosion resistance but relatively-low hardness and yield strength, ${ }^{1,2}$ leading to limited usage in applications that high values of hardness and wear resistance is necessary for material surface. Therefore, surface properties such as hardness must be improved using appropriate techniques. Mechanical surface treatments such as ultrasonic shot peening, ${ }^{3,4}$ laser shock peening, ${ }^{5,6}$ burnishing ${ }^{7,8}$ and deep rolling ${ }^{9,10}$ are appropriate methods for surface grain refinement, resulting in improvement of surface hardness and other properties of austenitic stainless steels. Among them, deep rolling is a well-known method for increase of surface regions hardness with a thick affected depth. These days, the processing of crankshafts, surgical implants, turbine blades, oil field equipment, components of engines and gear boxes, welded joints, tension bolts and bend shafts, holes, valve bodies for high pressure compressors, components of cooling pumps and aircraft instruments are the most well-known applications of ball-point deep rolling in the metals such as ASSs.

In deep cold rolling treatment also known as "Deep Rolling", a ball or roller is pressed against the part surface. ${ }^{11}$ When a load is applied on the ball, the force generates a high Hertzian compressive stress state in the material at its contact point. Therefore, a 3D stress situation appears when contacting the part surface, resulting in the plastic deformation as soon as the yield point of the material is exceeded. While the tool and/or part are rotating, the plastic deformation progresses continuously over the entire surface. It is fast, effective and inexpensive process. Deep rolling can provide deep and high compressive residual stresses. Work hardening (i.e. increase in surface microhardness) is another effect of this process. The achievement of three physical effects, namely the formation of compressive residual stresses, work hardening and achievement of quality surface finish, makes deep rolling one of the most effective and reliable techniques among the others. ${ }^{11}$ Formation of nano/ultrafine grains, mechanical twins and strain-induced marten site are some structural alterations of austenitic stainless steels after applying of deep rolling process. ${ }^{12}$

The high strength of stainless steels may be mainly attributed to the high-strength constituent, such as marten site. The $316 \mathrm{~L}$ stainless steel contains thermodynamically met stable austenite at room temperature, which can be transformed to martensite (straininduced martensite, SIM) by deformation below the $\mathrm{M}_{\mathrm{d} 30}{ }^{13} \mathrm{M}_{\mathrm{d} 30}$ is the temperature that $50 \%$ martensite is formed in microstructure at $30 \%$ true strain. The volume fraction of SIM increases with increasing of strain. The martensite formation becomes saturated at a specific strain called 'saturating strain' $\left(\varepsilon_{s}\right)$. The martensite crushes during deformation, increasing the concentration of lattice defects inside the SIM. Dislocations act as a suitable site for martensite nucleation in

the method. The volume fraction of martensite and $\varepsilon_{s}$ play important roles in achieving nano/ultrafine structure. ${ }^{13}$ Therefore, deep rolling as a severe plastic deformation treatment can induce strain-induced martens tic transformation in near-surface of ASSs, resulting in further surface hardness. In addition, formation of the deformation (slip) bands identified as mechanical twins is observed in austenitic stainless steels. The martenstic transformation can be referred to the formation of intersecting mechanical twinning's near the surface regions, because of the relatively low stacking-fault energy of austenitic stainless steels $\left(17 \mathrm{~mJ} / \mathrm{m}^{2}\right) \cdot{ }^{13,14}$ The similar behavior has been reported in the plastic deformation of austenitic stainless steels by several mechanical surface treatments. ${ }^{13-15}$

Several experimental practices recently reported by investigators about effects of mechanical surface treatments on structural characteristics and properties of austenitic stainless steels are as follows..$^{12,14-18}$ Nikitin et al. ${ }^{16}$ studied effects of the single-pass deep rolling at room temperature on structure of the AISI 304 stainless steel. A nanocrystalline layer of strain-induced martensite and remained austenite with $80 \mathrm{~nm}$ grain size and $2 \mu \mathrm{m}$ thickness was induced in near-surface using this process. The depth of straininduced martensite was measured about $400 \mu \mathrm{m}$. Moreover, a mixture of dislocation tangles, mechanical twinning's and carbide ingredients was formed in surface regions. Altenberger et al. ${ }^{12}$ and Nikitin et al. ${ }^{17}$ induced a surface nanostructure and strain-induced martensitic layer with thicknesses of 2 and $200 \mu \mathrm{m}$ in the deep rolled AISI 304 stainless steel. It was found the strain-induced martensite phase value 
is reduced with temperature increasing. The treatment increased surface hardness from 200 to $360 \mathrm{HV}_{05}$. Hashemi et al. ${ }^{18}$ formed a surface refined-grain structure in the AISI $316 \mathrm{~L}$ stainless steel by shot peening, increasing surface hardness from 250 to $450 \mathrm{HV}_{0.5}$. Moreover, surface affected depth, induced by shot peening, was achieved about $100-150 \mu \mathrm{m}$. Sun ${ }^{14}$ exhibited surface nanostructure, formed on the mechanical attrition treated AISI 304 stainless steel, improves surface hardness from 200 to about $450 \mathrm{HV}_{01}$ and significantly wear resistance. Maximum thickness of surface affected layer was achieved about $200 \mu \mathrm{m}$. Lin et al. ${ }^{15}$ showed that surface mechanical attrition treatment increases near-surface hardness of the AISI 321 stainless steel through surface nano-crystallization. A surface nanocrystalline structure, characterised by equiaxed grains with $10 \mathrm{~nm}$ grain size, was produced using applied treatment, resulting in increase of surface hardness from 200 to about $450 \mathrm{HV}_{0.025}$.

In most of the previous works, deep rolling has been applied at single pass, leading to a narrow affected depth in surface layers. Therefore, the present paper has been focused on achievement a thick deformed layer with high values of hardness in near surface regions of the deep rolling processed AISI316L stainless steel. Hence, the process was done at multiple passes on the bar-shaped steel. For accurate observation of microstructure, field emission scanning electron microscope (FESEM) was employed. In addition, $\mathrm{X}$-ray diffractometer (XRD) and feritscope were used for phasic characterization as well as micro-hardness tester for hardness measurement.

\section{Material and experimental procedure}

\section{Material}

A hot-rolled bar of the AISI 316L austenitic stainless steel with $30 \mathrm{~mm}$ diameter, $210 \pm 5 \mathrm{HV}_{0.1}$ average hardness and chemical composition (wt.\%): $0.03 \mathrm{C}, 17.50 \mathrm{Cr}, 10.50 \mathrm{Ni}, 2.15 \mathrm{Mo}, 1.81 \mathrm{Mn}$, $0.50 \mathrm{Si}, 0.04 \mathrm{P}, 0.03 \mathrm{~S}$ and balance $\mathrm{Fe}$ was received as the substrate material. Microstructure of the as-received $316 \mathrm{~L}$ stainless steel (named UT) prepared through $\mathrm{SiC}$ grinding and mechanical polishing, and then etching by $20 \mathrm{ml} \mathrm{HCL}+10 \mathrm{ml} \mathrm{HNO}_{3}+20 \mathrm{ml} \mathrm{H}_{2} \mathrm{O}$ solution was only austenite phase with $25 \mu \mathrm{m}$ average grain size as shown in Figure 1

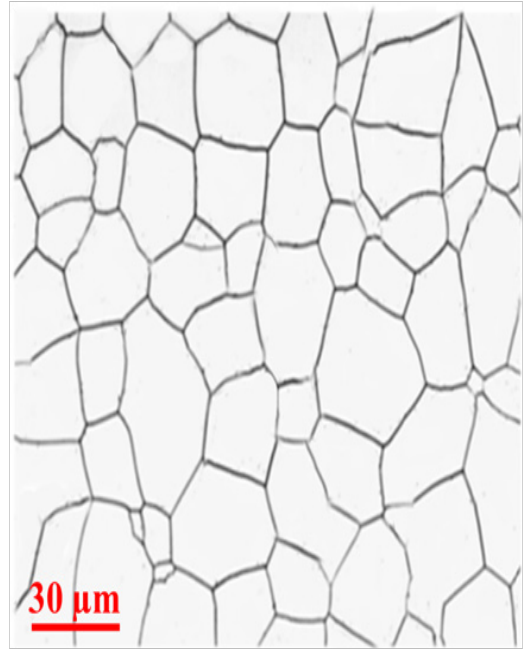

Figure I Optical micrograph showing microstructure of the as-received AISI 3I6L stainless steel.

\section{Deep rolling process}

The room temperature deep rolling process was performed by a "ball-point" rolling device equipped by a high-rigid tungsten carbide (WC) ball with $20 \mathrm{~mm}$ diameter and $1400 \mathrm{HV}_{30}$ hardness. Experimental set-up of the deep rolling treatment is schematically illustrated in Figure 2. For conducting the process, the rolling device was steadily pressed against the surface of the rotary steel bar with constant velocity of $\mathrm{V}_{1}$ and simultaneously the rolling device glides at constant velocity of $\mathrm{V}_{2}$ parallel to bar axis from right to left (and inverse), selection of $22.4 \mathrm{rpm}$ and $0.2 \mathrm{~mm} / \mathrm{s}$ values for $\mathrm{V}_{1}$ and $\mathrm{V}_{2}$ parameters, respectively. During the process, oil lubricant was added between the work-piece and WC ball. In order to increase the grains surface refinement and creation of further hardness, the deep rolling was performed at multiple passes (15 and 26 passes). In the first process, the rolling device glided 15 times along the axis of the workpiece with $25 \mu \mathrm{m}$ device feed for each sweep (DRI process) and 26 times with similar device feed at the second process (DRII process). Total feed of the device was respectively reached to 400 and $650 \mu \mathrm{m}$ after 15 and 26 passes, leading to 110 and $160 \mu \mathrm{m}$ reduction of bar diameter after DRI and DRII processes, respectively. The mentioned conditions of the process were selected with regarding the characters of equipment and, trial and error to achieve of an appropriate plastic deformation in the material. With increasing of the device feed, a higher force is applied on the part surface, resulting in further surface plastic deformation. The bar reduction in diameter were measured by an appropriate caliper at different points and average value was selected as final reduction of bar diameter.

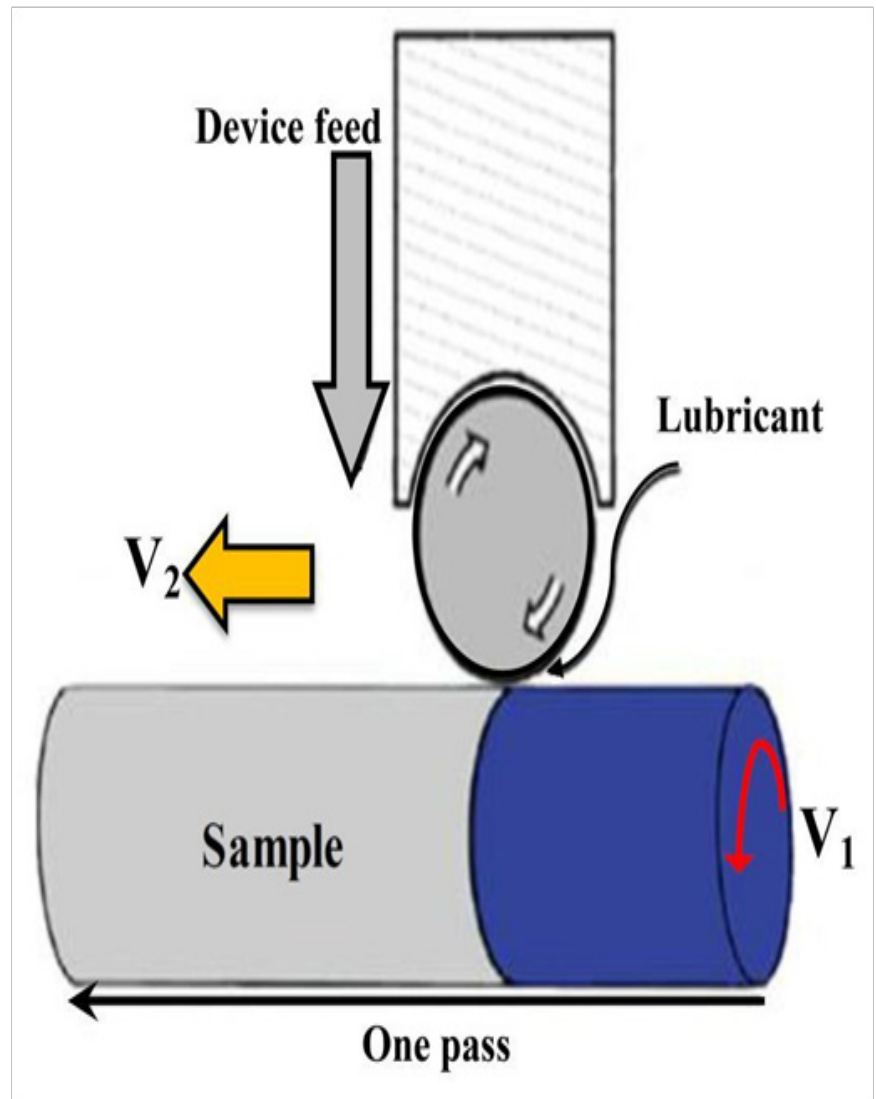

Figure 2 Experimental set-up of the performed deep rolling treatment. 


\section{Characterization of the surface}

Cross-sections of the deep-rolled specimens were ground and then polished to achievement a smooth surface. Solution of $10 \mathrm{ml}$ $\mathrm{HCL}+10 \mathrm{ml} \mathrm{HNO}_{3}+10 \mathrm{ml}$ acetic acid $+67 \mu$ l glycerol was used for etching of the samples. A PME3 optical microscope (OM) and ZEISS field emission scanning electron microscope (FESEM) at SE state with $15 \mathrm{kV}$ voltage were employed for microstructure observation. Deformed depth and grains size were measured using FESEM, which was an appropriate device for illustrating nano-grains. Phasic characterization related to the as-received and deep rolled samples was done using feritscope (Fischer FMP30) and X-ray diffractometer (MPD-X'PERT) performed using a $\mathrm{Cu} \mathrm{K} \alpha$ radiation with $1.542515 \mathrm{~A}^{\circ}$ wave length, 30 to $100^{\circ}$ scanning range, $0.05^{\circ}$ step size and $1 \mathrm{sec}$ scan step. Micro-hardness was measured by Vickers method at $0.1 \mathrm{~kg}$.f load, which it is an appropriate load for the manufactured samples with considering to capability of micro-hardness tester.

\section{Results and discussion}

\section{Structural evaluations}

Figure 3 shows a FESEM micrograph from cross-section morphology of the DRI processed sample (15 passes) from surface to the substrate. Deep rolling leads to a complex microstructure in the surface regions of austenitic stainless steels. ${ }^{16,17}$ Three different zones, consisting of bakelite (B), affected zone and substrate (S) are shown in Figure 3. The affected zone has been composed from two different parts. In the first part (named "G"), formation of new refined grains $(\mathrm{G})$ inside primary micro-sized grains is the main structural change. Further details of this part are shown in the next sections. In the second part (characterised by "T"), lamellar (LT) and intersecting (IT) mechanical twins have embraced major part of the structure, a prevalent tendency in plastic deformed austenitic stainless steels agreed with previous works. ${ }^{14-18}$ According to later works, formation of equiaxed ultrafine/nanosize crystallines and then mechanical twins with depth increasing is a general trend in mechanical surface treated austenitic stainless steels, good according with image observed in Figure 3. It is noticeable that characterized mechanical twins may be deformation bands. Deformation band is a collective term for the planar defects that form as a result of the overlapping of stacking faults on austenite $\{111\}$ planes during the plastic deformation. ${ }^{13}$ Hence, since deformation bands and mechanical twins are similar and have a planar structure may be confused with each other. On the other hand, the new refined grains are populated by deformation bands identified as mechanical twins for such austenitic stainless steel with relatively-low stacking fault energy. ${ }^{14}$ Since, at major previous works such as Reference, ${ }^{14-18}$ formation of nano/ultrafine grains next to the mechanical twins (not deformation bands) has been reported, hence LT and IT are supposed as the mechanical twins.

The strain-induced martensitic transformation is another prevailed phenomenon in plastic deformed austenitic steels. ${ }^{13-20}$ In austenitic stainless steels, formation of martensite phase is achieved at locale of twins intersecting. On the other hand, intersection of two sets of mechanical twins leads to transformation of austenitic phase to martensitic kind. ${ }^{13-20}$ Due to observation and recognizing of martensitic phase by SEM needs to the BSE detector, LT and IT cannot be strain-induced martensite. Refined grains and mechanical twins have not been formed in the substrate $(\mathrm{S})$, due to the low strain induction by the performed deep rolling.

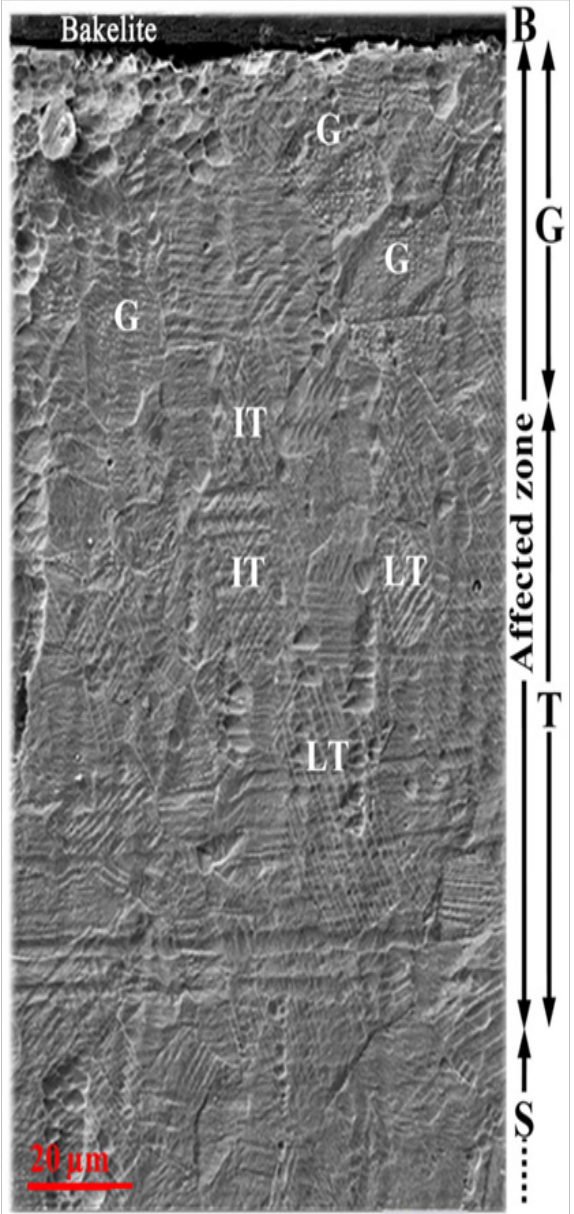

Figure 3 FESEM micrograph showing the cross-section morphology of the DRI processed steel (I5 passes) from surface to substrate

FESEM micrograph from cross-section of near-surface regions related to Figure 3 with higher details is shown in Figure 4. As can be seen, equiaxed refined grains $(G)$ have been formed near to the surface layers and inside primary micro-size grains, extending 50-60 $\mu \mathrm{m}$ into depth. Due to the texture effect in grain refinement, ultrafine grains have been formed inside some micro-sized grains. Lamellar (LT) and intersecting (IT) mechanical twins are shown at further depths of structure. Therefore, with depth increasing and thus reduction of strain induction, refined grains formed in the surface regions are followed by mechanical twins. A similar behavior has been so far seen in several works, such as in. ${ }^{12}$ In the later work, a surface nanocrystalline layer followed by mechanical twins has been formed in the deeprolled austenitic stainless steel. ${ }^{12}$ In comparison nano/ultrafine grains, formation of twins needs a lower strain induction. ${ }^{19}$ Hence, twins have a more formation depth, achieving about $170-200 \mu \mathrm{m}$ in the present work.

Morphology of the selected grain (\#) related to Figure 4 with further details is seen in Figure 5. Such as the as-received material, large-angle or primary boundaries (PB) are observed in this figure. But, equiaxed grains $(G)$ with an average diameter near to $200 \mathrm{~nm}$ have been formed inside primary micro-sized grains. Therefore, without elimination of large-angle boundaries, ultrafine grains and twins have been formed in the surface layers using the performed deep rolling. According to the studies, formation of intersecting mechanical twins 
(or deformation bands) with nano/ultrafine size leads to the induction of equal-size grains inside primary grains at such austenitic stainless steel. ${ }^{19}$ In general, intersecting mechanical twins with lower sizes are formed near to surface regions contained highest value of induced strain and then transformed to the nano/ultrafine grains. ${ }^{20}$ While, lamellar and intersecting mechanical twins with further sizes and without any refined grain are formed in high depths contained lower strain. ${ }^{20}$ For example, selected lamellar twins (LT) in Figure 3 have about $1200 \mathrm{~nm}$ thickness and refined grains are not shown in this part.

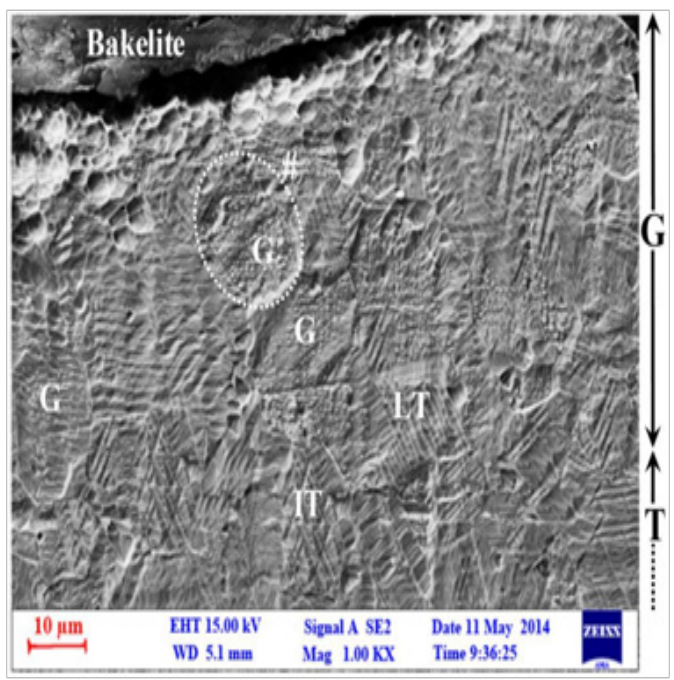

Figure 4 FESEM micrograph showing the microstructure of near-surface regions of the deep rolled steel (DRI).

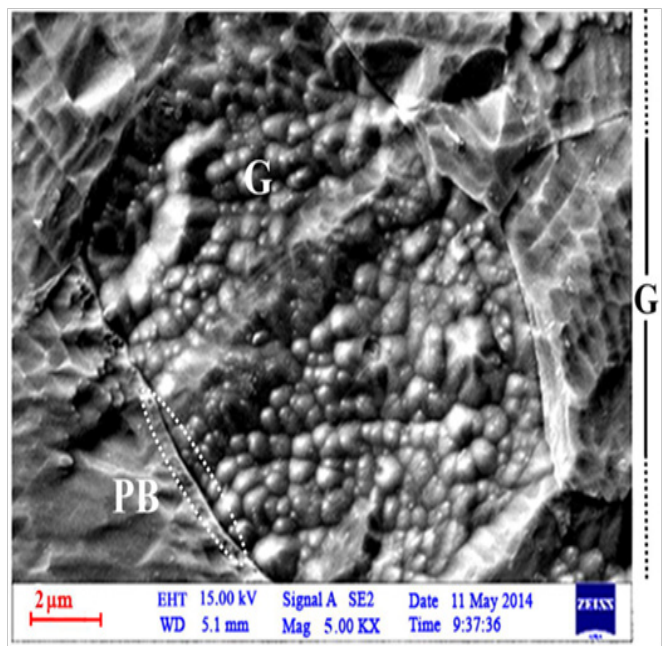

Figure 5 FESEM micrograph showing the ultrafine equiaxed grains inside original micro-sized grain of the DRI processed steel.

While at low depths of Figure 4, thickness of lamellar twin (LT) is near to $400 \mathrm{~nm}$ and refined grains are shown in this part. This trend is shown in Figure 3 that with strain decreasing from surface to substrate, ultrafine grains and then mechanical twins have been respectively formed in the micrograph. Induction of mechanical twins next to nano/ultrafine grains, due to relatively low $\operatorname{SFE}\left(17 \mathrm{~mJ} / \mathrm{m}^{2}\right)$ is a prevalent tendency during deformation of austenitic stainless steels. ${ }^{21}$ Similar behavior has been seen in several previous works. ${ }^{12,13,16,17}$ In these works, mechanical surface treatments, consisting of mechanical attrition, shot peening and deep rolling created a mixture of nano ultrafine grains and mechanical twins in several austenitic stainless steel. In the substrate zone (S) of Figure 3, there is no refined grain and mechanical twinning, due to lack of induction of an effective strain in this part of the material.

Figure 6 presents a FESEM micrograph from cross-section of topsurface regions of the DRII processed steel (26 passes). According to this figure, nanosize equiaxed grains $(\mathrm{G})$ without any presence of original grains (primary boundaries) and mechanical twins have been formed in the top-surface layer of the steel. Equiaxed grains with $70 \mathrm{~nm}$ average size and random orientations are shown in this section of figure. In comparison with DRI process, further internal strain fields are induced in DRII type resulted by higher passes, which these fields have been led to dynamic recrystallization in surface layers of the deep rolled material (DRII). Therefore, new nanosize equiaxed grains are formed in the top-surface layer without any presence of twins, ultrafine grains $(200 \mathrm{~nm})$ and large-angle boundaries, which were observed in DRI type.

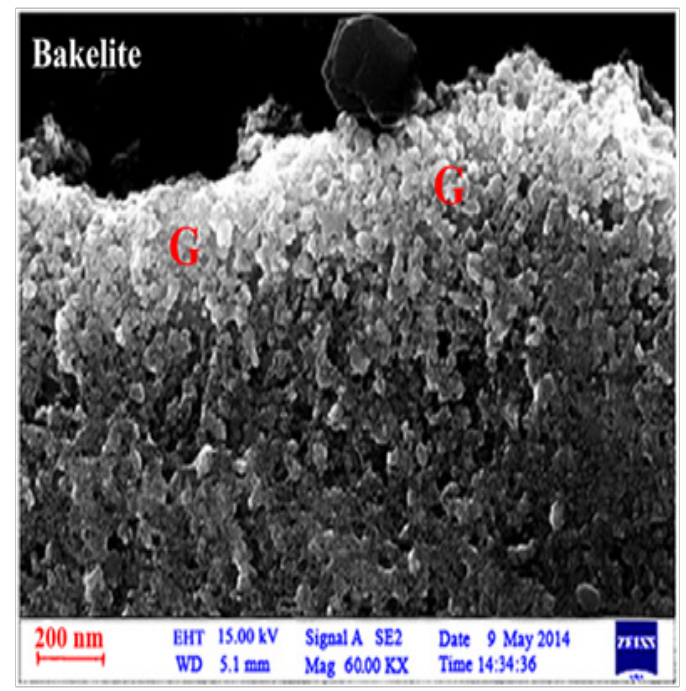

Figure 6 FESEM micrograph showing microstructure of the top-surface regions after the DRII process.

\section{Micro-hardness profiles}

Micro-hardness profiles related to the processed parts have been shown in Figure 7. According to this figure, surface hardness has been increased from 210 to 450 and $500 \mathrm{HV}_{0.1}$ after the deep rolling at 15 and 26 passes, respectively. But, surface hardness of an AISI 304 stainless steel has been increased from 200 to $360 \mathrm{HV}_{0.5}$ by single-passed deep rolling in a previous work. ${ }^{17}$ While multiple pass deep rolling in the present work created higher values of hardness in the used steel. It is noticeable that in the DRII sample, hardness at the depth of $50 \mu \mathrm{m}$ below the surface is higher than the top-surface layer. Transition of maximum-hardness peak from top surface to deeper layers is a relatively-usual tendency in deep rolled metals. ${ }^{22}$ This behavior is shown when work-hardening induced in top-surface layer is higher than the its saturated value, resulting in dynamic recrystallization at extra-hardened zones. ${ }^{22}$

This is at complete accordance with the top-surface structure of the DRII sample that has been recrystallized after 26 passes as shown in Figure 6. Moreover, temperature at contact point between the ball and surface material is higher than the deeper regions, ${ }^{16}$ resulting in a 
slightly grain growth as well as softening and therefore lower hardness at the top-surface layer. Hence, the lower hardness is achieved in the top-surface layer of the DRII sample compared to deeper regions (below $50 \mu \mathrm{m}$ ). With considering the relative-reduction of internal crystalline defects of DRII sample after dynamic recrystallization and slightly grain growth, it may be told general stability of the obtained nano layer is higher than DRI, but at higher temperatures some grain growth is achieved in the DRII structure.

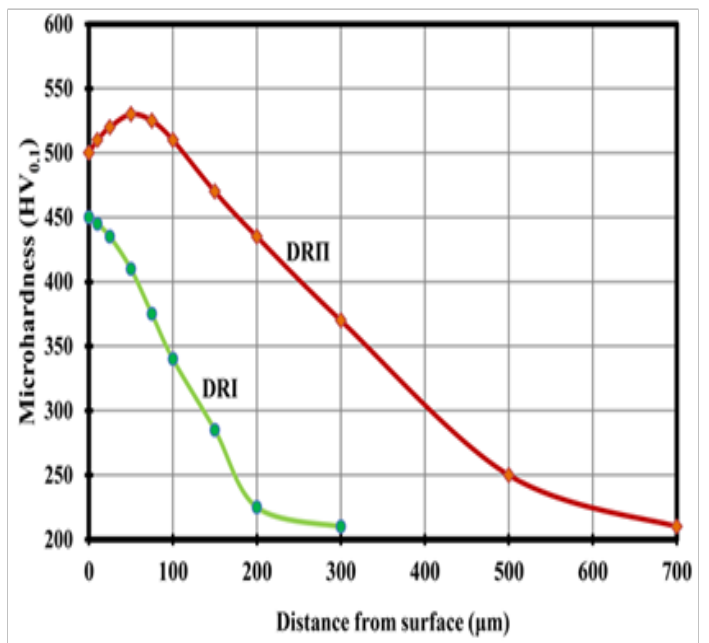

Figure 7 The micro-hardness profiles of the DRI and DRII processed samples.

Due to the further passes, higher affected depth about $700 \mu \mathrm{m}$ has been achieved in the DRII specimen than that of the DRI, $300 \mu \mathrm{m}$. As a comparison, the deep rolling at single pass at a previous work ${ }^{14}$ induced about $360 \mathrm{HV}_{0.5}$ hardness, while further hardness was achieved by performed multiple deep rolling. Moreover, shot peening in Reference ${ }^{18}$ induced $450 \mathrm{HV}_{0.5}$ hardness in the AISI 316L stainless steel $\left(250 \mathrm{HV}_{05}\right.$ substrate hardness) with about $100-150 \mu \mathrm{m}$ surface affected depth. While, the applied deep rolling further hardness with further affected depths induced in this work. In addition, Lin et al. ${ }^{15}$ exhibited that SMAT increases near-surface hardness of the AISI 321 stainless steel from 200 to about $450 \mathrm{HV}_{0.025}$ only at about $20 \mu \mathrm{m}$ depth.

\section{Phasic analysis}

Figure 8 shows X-ray diffraction patterns of the as-received and deep rolled specimens. The as-received sample (UT) only consists of austenitic phase $(\gamma)$, while the deep-rolled parts have been composed of retained austenite $(\gamma)$ and strain-induced martensite $\left(\alpha^{\prime}\right)$. The (110), (200), (211) and (220) planes of the $\alpha$ ' phase are shown in both the DRI and DRII patterns. Due to the higher mechanical-working, higher-intensity martensitic peaks has been diffracted in the DRII processed than that of DRI one. The martensitic transformation can be attributed to the formation of intersecting twins in the surface layers, due to the relatively low stacking-fault energy of austenitic stainless steels. ${ }^{19-23}$ The feritscopy measurements showed that 8 and $11 \mathrm{Vol} . \%$ of $\alpha$ martensite have been formed in the deformed zones of the DRI and DRII processed kinds, respectively. Comparison of X-ray patterns and feritscopy measurements reveals that a further amount of martensite (about 11 Vol.\%) has been produced in the DRII sample with higher intensity of martensite peaks.

It is clear that surface hardness has been increased with formation of retained austenite and strain-induced martensite according to
Figures $7 \&$ Figure 8 . Therefore, surface hardness of DRII should be further than that of the DRI due to the more hardness of martensite phase. While, the DRII kind with further intensity of martensite peaks displays lower surface hardness than the DRI one. According to the micro-hardness profile and the structural aspects mentioned at the above texts, this is due to the slightly grain growth as well as softening, resulting in lower hardness at the top-surface layer. Therefore, the deep rolling at higher passes (DRII process) induced a structure, consisting of more martensitic phase and lower-size austenitic grains with higher affected depth, as well as more surface hardness as shown in Figures 6-8.

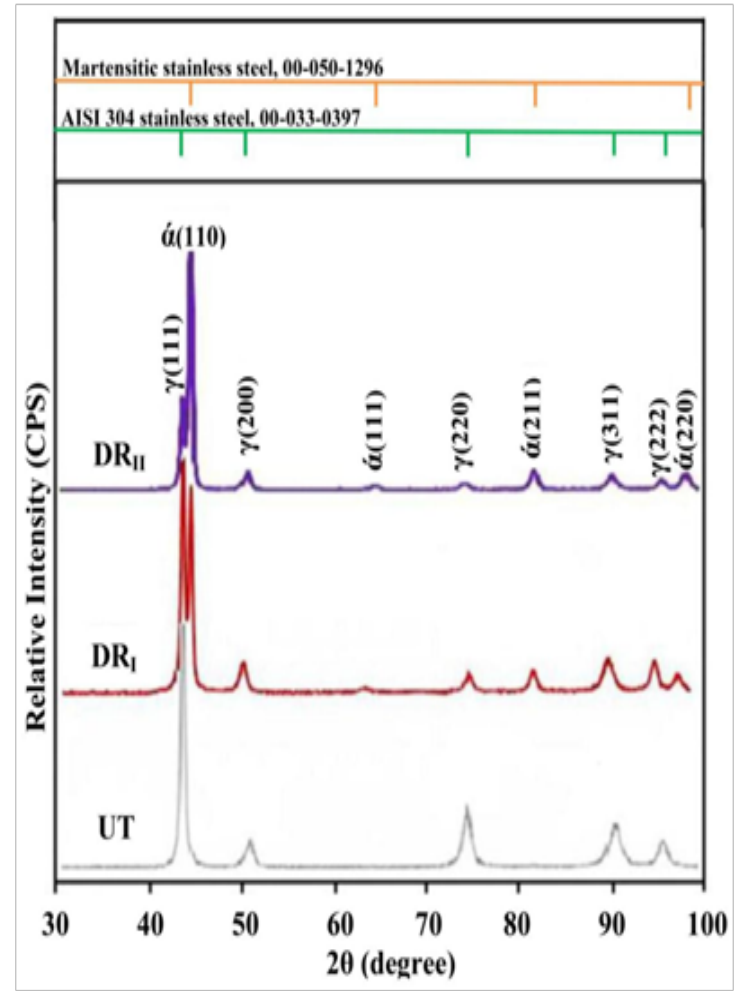

Figure 8 X-ray diffraction patterns of the as-received and deep rolled samples.

\section{Conclusion}

i. Surface mechanical treatments such as deep rolling are appropriate methods for surface grain refinement and thus surface alteration of the properties.

ii. Deep rolling process induced nano-size and ultrafine grains in the surface layers of the AISI $316 \mathrm{~L}$ stainless steel.

iii. Strain-induced martensitic transformation was another structural change after the deep rolling.

iv. Grain refinement and martensitic transformation was enhanced by increase the number of pass.

v. Surface hardness was increased from 210 to 450 and $500 \mathrm{HV}_{0.1}$ with a gradual slope after the performed deep rolling.

vi. Surface hardness was enhanced by increase the number of pass.

vii. Relatively-high affected depths were achieved in the deep-rolled specimens, due to the high number of pass. 


\section{Acknowledgements}

None.

\section{Conflict of interest}

The author declares no conflict of interest.

\section{References}

1. Davis JR. ASM Specialty Handbook: Stainless Steel. 4th ed. USA: Metals Park; 1994

2. Lula RA. Stainless Steel. Metals Park, USA: American Society for Metals; 1985.

3. Liu G, Lu J, Lu K. Surface nanocrystallization of 316L stainless steel induced by ultrasonic shot peening. Materials Science and Engineering A. 2000;286(1):91-95.

4. Shen L, Wang L, Wang Y. Plasma nitriding of AISI 304 austenitic stainless steel with pre shot peening. Surface and Coatings Technology. 2010;204(20):3222-3227.

5. Mordyuk BN, Milman YV, Iefimov MO, et al. Characterisation of ultrasonically peened and laser shock peened surface layers of AISI 321 stainless steel. Surface and Coatings Technology. 2008;202(19):48754883 .

6. Lim H, Kim P, Jeong H, et al. Enhancement of abrasion and corrosion resistance of duplex stainless steel by laser shock peening. Journal of Materials Processing Technology. 2012;212(6):1347-1354.

7. Malleswara JN, Chenna A, Rama PV. The effect of roller burnishing on surface hardness and surface roughness on mild steel specimens. $I J$ Appl Eng Re. 2011;1(4):777-785.

8. Thamizhmnai S, Bin Omar B, Saparudin S, et al. Surface roughness investigation and hardness by burnishing on titanium alloy. $J$ Ach Mater Manuf Eng. 2008;28(2):139-142.

9. Zhuang W, Liu Q, Djugum R, et al. Deep surface rolling for fatigue life enhancement of laser clad aircraft aluminum alloy. Applied Surface Science. 2014;320:558-562.

10. Daniel Meyer. Cryogenic deep rolling-An energy based approach for enhanced cold surface hardening. CIRP Annals. 2012;61(1):543-546.

11. Prabhu PR, Kulkarni SM, Sharma SS. Influence of deep cold rolling and low plasticity burnishing on surface hardness and surface roughness of AISI 4140 steel. Sc Eng Tech. 2010;72:619.
12. Altenberger, Scholtes B, Martin U, et al. Cyclic deformation and near surface microstructures of shot peened or deep rolled austenitic stainless steel AISI 304. Materials Science and Engineering A . 1999;264(1-2):116.

13. Eskandari M, Najafizadeh A, Kermanpur A. Effect of strain-induced martensite on the formation of nanocrystalline $316 \mathrm{~L}$ stainless steel after cold rolling and annealing. Materials Science and Engineering A. 2009;519(1-2):46-50.

14. Sun Y. Sliding wear behavior of surface mechanical attrition treated AISI 304 stainless steel. Tribology International. 2013;57:67-75.

15. Lin Y, Lu J, Wang L, et al. Surface nanocrystallization by surface mechanical attrition treatment and its effect on structure and properties of plasma nitrided AISI 321 stainless steel. Acta Materialia. 2006;54(20):5599-605.

16. Nikitin I, Altenberger I, Scholtes B. Effects of deep rolling at elevated and low temperatures on the isothermal fatigue of A1S1304. Alternative Processes. 2005;70:185-190.

17. Nikitin, Altenberger I. Comparison of the fatigue behavior and residual stress stability of laser-shock peened and deep rolled austenitic stainless steel AISI 304 in the temperature range $25-600^{\circ}$ C. Mater Sc Eng. 2007;465:176-182.

18. Hashemi B, RezaeeYazdi M, Azar V. The wear and corrosion resistance of shot peened-nitrided 316L austenitic stainless steel. Materials \& Design. 2011;32(6):3287-3292.

19. Tao N, Zhang H, Lu J, et al. Development of nanostructures in metallic materials with low stacking fault energies during surface mechanical attrition treatment (SMAT). Mater Trans. 2003;44(10):1919-1925.

20. Tao NR, Lu J, Lu K. Surface nanocrystallization by surface mechanical attrition treatment. Materials Science Forum. 2008;579:91-108.

21. Lo KH, Shek CH, La JKL. Recent developments in stainless steels. Materials Science and Engineering R Reports. 2009;65(4-6):39-104.

22. Altenberger. Deep rolling-the past, the present and the future. Alternative Processes. 2005;65:144-155.

23. Golzar Shahri M, Hosseini SR, Salehi M. Formation of nano/ultrafine grains in AISI 321 stainless steel using advanced thermo-mechanical process. Acta Metallurgica Sinica. 2015;28(4):499-504. 